\title{
Localization of Thioredoxin in the Rat Brain and Functional Implications
}

\author{
Andrea Lippoldt, ${ }^{1,3}$ C. Alicia Padilla, ${ }^{2}$ Hellmut Gerst, ${ }^{1}$ Beth Andbjer, ${ }^{3}$ Edith Richter, ${ }^{1}$ Arne Holmgren, ${ }^{2}$ and Kjell \\ Fuxe $^{3}$ \\ 'Max-Delbrück-Center for Molecular Medicine Berlin-Buch, Germany, ${ }^{2}$ The Medical Nobel Institute, Department of \\ Biochemistry I, Karolinska Institute, Stockholm, Sweden, and ${ }^{3}$ Department of Neuroscience, Division of Cellular and \\ Molecular Neurochemistry, Karolinska Institute, Stockholm, Sweden
}

The immunoreactivity for thioredoxin, which catalyzes protein disulfide reductions, has previously been shown to exist in nerve cells and their axons. Here we demonstrate the localization of thioredoxin mRNA as revealed by in situ hybridization in the rat brain. The gene is expressed in nerve cells of a variety of brain regions, for example, the cerebral cortex, the piriform cortex, the medial preoptic area, the CA3/CA4 region of the hippocampal formation, the dentate gyrus, the paraventricular nucleus of the hypothalamus, the arcuate nucleus, the substantia nigra pars compacta, the locus coeruleus, the ependyma of the 4th ventricle, and the epithelial cells of the choroid plexus. This distribution implicates an important function in nerve cell metabolism, especially in regions with high energy demands and indicates a role of the choroid plexus in nerve cell protection from environmental influences. It was found that after mechanical injury induced by partial unilateral hemitransection the thioredoxin mRNA expression is upregulated in the lesioned area and spreads to the cortical hemispheres at the lesioned level. This induction suggests a function of thioredoxin in the regeneration machinery of the brain following mechanical injury and oxidative stress.

[Key words: thioredoxin, $m R N A$, in situ hybridization, brain, rat, hemitransection]

Thioredoxin is a multifunctional $12 \mathrm{kDa}$ protein which catalyzes reductions of protein disulfides via an active site dithiol with the sequence-Cys-Gly-Pro-Cys-. As part of the thioredoxin system, that is, thioredoxin, NADPH, and FAD-containing enzyme thioredoxin reductase, thioredoxin is a hydrogen donor for ribonucleotide reductase, methionine sulfoxide reductases, or sulfate reductase. It is also a general protein disulfide reductase and regulates enzyme and protein activity by "thiol redox control" (Holmgren, 1985, 1989).

Thioredoxin has been isolated from a large variety of procaryotic and eukaryotic species, making it ubiquitous (Holmgren

Received Feb. 13, 1995; revised June 6, 1995; accepted June 12, 1995.

This study was supported by grants from the Swedish Medical Research Council $(04 \times 715,13 \times-3529)$ and a grant from Petrus and Augusta Hedlunds Stiftelse. A.L. was supported by the Deutsche Forschungsgemeinschaft (SFB 317 , Li $604 / 1-1)$. C.A.P. was supported by a fellowship from the European Community.

Correspondence should be addressed to Dr. Andrea Lippoldt, Max-DelbrückCenter for Molecular Medicine, Berlin-Buch Robert-Rössle-Strasse 10, 13125 Berlin, Germany.

Copyright $\odot 1995$ Society for Neuroscience $\quad 0270-6474 / 95 / 156747-10 \$ 05.00 / 0$
1985). In mammals, thioredoxin and thioredoxin reductase are widespread in different tissues and not only related to cellular growth and DNA synthesis (Holmgren, 1985; Hansson et al., $1986 \mathrm{a}, \mathrm{b})$. High levels of thioredoxin and thioredoxin reductase are present in nervous tissue, for example, in nerve cells and their axons (Rozell et al., 1985; Stemme et al., 1985). Thioredoxin is localized at intracellular membranes especially in secretory cells (Hansson et al., 1986a, 1989). Using antisera against rat thioredoxin the protein was observed to be widely distributed and its immunoreactivity is localized in the cytoplasm and enriched at plasma membranes or in the subplasma membrane zone. Thioredoxin levels vary in secretory cells dependent on their stage of metabolic activity (Hansson et al., 1986a, 1988, 1989). Recent results have identified thioredoxin as a secreted growth factor (Tagaya et al., 1989; Ericson et al., 1992) and a regulator of transcription factors (Matthews, 1992).

The cDNA encoding human thioredoxin has been cloned (Wollman et al., 1988; Tagaya et al., 1989; Tonissen and Wells, 1991). It is not known so far, in which nuclei of the mammalian brain the message is expressed and how this is related to functional aspects and electron transport to reductive enzymes. In the present article the first demonstration of the cellular localization and distribution of thioredoxin mRNA levels is given together with evidence for an involvement of thioredoxin in brain plasticity as seen from an upregulation of thioredoxin mRNA levels after a partial mesodiencephalic hemitransection.

\section{Materials and Methods}

Animals. Male pathogen-free adult Sprague-Dawley rats (200 gm average body weight) were used for thioredoxin mRNA localization (four rats) and for thioredoxin mRNA localization after partial mesodiencephalic hemitransection (20 rats). They were kept under regular lighting conditions (lights on 6:00 A.M. and off 8:00 P.M.) at constant temperature $\left(23^{\circ} \mathrm{C}\right)$ and had free access to food pellets and tap water.

Partial meso-diencephalic hemitransection. The anaesthetized rats (chloralhydrate $350 \mathrm{mg} / \mathrm{kg}$ body weight) were mounted in a stereotactic instrument (David Kopf, Tujunga, CA). After drilling out a circularshaped piece of skull bone, the dura was penetrated with a rectangular knife ( $4 \mathrm{~mm}$ wide, $1 \mathrm{~mm}$ thick at the edge), which was tilted $20^{\circ}$ to the frontal plane and inserted $1 \mathrm{~mm}$ caudal to bregma and $1 \mathrm{~mm}$ lateral to the midline (bregma $-1.00 \mathrm{~mm}, \mathrm{~L}+1.00 \mathrm{~mm}$; Paxinos and Watson, 1986). The knife was lowered $10 \mathrm{~mm}$ ventrocaudally into the right hemisphere. After touching the skull base it was withdrawn $2 \mathrm{~mm}$, moved laterally until touching the bone and then removed.

The lesion cuts ascending and descending pathways including the nigrostriatal dopaminergic system with the exception of its most medial components (Agnati et al., 1983). As controls sham-operated rats were used (four rats). The rats were studied at several timc-points aftcr hemitransection: $24 \mathrm{hr}, 72 \mathrm{hr}, 7 \mathrm{~d}, 14 \mathrm{~d}$ (four rats in each group). 
The body weight of the hemitransected rats decreased significantly 7 d after surgery as compared to sham operated rats and was still significantly less compared to sham operated rats at the $14 \mathrm{~d}$ time interval. However, at the $14 \mathrm{~d}$ time point the body weight was comparable to the basal value (Fuxe et al. 1990).

Dissection and fixation. For in situ hybridization studies the animals were anaesthetized with pentobarbital ( $60 \mathrm{mg} / \mathrm{kg}$ body weight) and transcardially perfused through the left cardiac ventricle with ice-cold $0.9 \%$ $\mathrm{NaCl}$. The brain was removed and snap frozen in isopentane $\left(-35^{\circ} \mathrm{C}\right)$. All material was sectioned at a $12 \mu \mathrm{m}$ thickness in a cryostat (Leica, Frigocut, Germany).

DNA construct. A human thioredoxin cDNA (open reading frame coding for 105 amino acid residues) (Tagaya et al., 1989) subcloned into plasmid pACA (Ren et al., 1993) was isolated by EcoRI digestion and subsequently subcloned into the EcoRI site of the pGEM $3 Z$ vector. The orientation of the insert in different subclones was analyzed by nucleotide sequence analysis (Sanger et al., 1977) using T7 RNA polymerase (Promega, Madison, WI). Two subclones with opposite orientation were selected and digested with SmaI. Sense and antisense RNA were obtained using T7 RNA polymerase for in vitro transcription.

RNA probe synthesis. The probes were synthesized by in vitro transcription using the T7 RNA polymerase promoter for sense (s) and antisense (as) RNA production as well. For this purpose the constructs were cut with SmaI. The probes were synthesized according to the standard procedure described earlier (Bunnemann et al., 1992). Briefly, ${ }^{35}$ S- $\alpha$-UTP (Du Pont NEN, Boston) was used to label the RNA transcripts in a mixture containing ribonucleotides, transcription buffer, $\mathrm{RN}$ ase inhibitor (Boehringer Mannheim, Germany) and T7 RNA polymerase (Boehringer Mannheim, FRG) for $90 \mathrm{~min}$ at $37^{\circ} \mathrm{C}$. Subsequentely, the DNA template was removed by treatment with RNase frec DNase I (Boehringer Mannheim, Germany) for $20 \mathrm{~min}$ at $37^{\circ} \mathrm{C}$. The transcripts were purified chromatographically on NENSORB cartridges (Du PontNEN, Boston, MA) and checked by denaturing formaldehyde gel electrophoresis. The specific activity of the probes was in the order of $5 \times$ $10^{8} \mathrm{dpm} / \mu \mathrm{g}$ RNA.

In situ hybridization. The procedure is described earlier in detail (Lippoldt et al., 1993). Briefly, the sections were brought to room temperature, fixed with $4 \%$ buffered paraformaldehyde, washed in PBS and deproteinized in $0.1 \mathrm{M} \mathrm{HCl}$. After additional washing the sections were acetylated to avoid unspecific binding. After dehydration in graded ethanols the sections were prehybridized in a humidified chamber with 150 $\mathrm{ml}$ of prehybridization buffer [50\% deionized formamide, $50 \mathrm{~mm}$ TrisHCl pH 7.6, $25 \mathrm{mM}$ EDTA pH 8.0, $20 \mathrm{mM} \mathrm{NaCl}, 0.25 \mathrm{mg} / \mathrm{ml}$ yeast tRNA, $2.5 \times$ Denhardt's solution $(0.05 \%$ Ficoll, $0.05 \%$ polyvinylpyrrolidone, $0.05 \%$ bovine serum albumin)] for $2-4 \mathrm{hr}$. After draining the prehybridization buffer off the slides, the sections were hybridized according to the standard procedure using $0.15 \mathrm{ng}$ of labeled $\mathrm{s}$ and as RNA, respectively. The hybridization was done at $37^{\circ} \mathrm{C}$ in a buffer containing 50\% formamide, $1 \times$ Denhardt's solution, $10 \%$ dextransulfate, $0.5 \mathrm{mg} / \mathrm{ml}$ yeast tRNA, $0.1 \mathrm{mg} / \mathrm{ml}$ poly-A, and $0.2 \mathrm{M} \mathrm{DTT} \mathrm{(for}$ details, see Lippoldt et al., 1993) for 16-18 hr. Thereafter. the slides were washed in $0.5 \times \mathrm{SSC} / 50 \%$ formamide at $48^{\circ} \mathrm{C}$ for $2 \mathrm{hr}, 20 \mathrm{~min}$ in $1 \times \mathrm{SSC}$ at $48^{\circ} \mathrm{C}$ and subsequently treated with RNase $\mathrm{A}(10 \mu \mathrm{g} /$ $\mathrm{ml}$ ) for $30 \mathrm{~min}$ at $37^{\circ} \mathrm{C}$ and washed several times in $1 \times \mathrm{SSC}, 0.5 \times$ SSC, and $0.2 \times \mathrm{SSC}$ at $48^{\circ} \mathrm{C}$, dehydrated in graded ethanols, dried, and exposed on Hyperfilm- ${ }^{3} \mathrm{H}$ films (Amersham, UK) and coated with Kodak NTB2 emulsion, respectively. The slides were exposed at $-20^{\circ} \mathrm{C}$ for 3 weeks on the $\mathrm{x}$-ray films and at $4^{\circ} \mathrm{C}$ for 6 weeks on emulsion. Emulsion coated slides were counterstained with cresyl violet.

The specificity of the method used was determined by hybridization with ${ }^{35} S-\alpha$-UTP labeled sense RNA at the same specific activity, length and concentration as the antisense RNA.

Computer-assisted microdensitometry. Semiquantitative data on the thioredoxin mRNA levels were obtained by measuring the gray values of the film autoradiograms using the microdensitometrical program of the IBAS 2.5 (Kontron, Germany) according to a previously published microdensitometric method (Zoli et al., 1990). Three measurements were performed for each region: (1) the total value, that is, measurements of the areas in question in the sections hybridized with ${ }^{35} \mathrm{~S}-\alpha-$ UTP-labeled thioredoxin-antisense RNA; (2) the unspecific value, that is, measurements of the corresponding areas in the control sections hybridized with ${ }^{35}$ S- $\alpha$-UTP-labeled thioredoxin-sense RNA; and (3) the background value, that is, measurements of the film background outside the sections. In order to obtain a rostrocaudal evaluation of the labeling intensity, the analyses were performed at various coronal levels. The autoradiograms were digitized directly via a TV camera (CCD 72/MTicamera) on a screen, allowing the measurement of an entire coronal section at once. The areas of interest were selected by means of a light pen and the transmissions were measured. The specific values were defined as those obtained by subtracting the nonspecific values (sections incubated with the labeled sense RNA-probe) from the total values (sections incubated with labeled antisense RNA-probe) after correcting for the background. Photographs of the in situ autoradiograms were directly taken from the $x$-ray film. Transmissions as well as optical densities were obtained utilizing postprocessing programs.

The measurement for the different regions was done as illustrated in Figure $4 a$ for the cortical parts at all time points. Since at the $24 \mathrm{hr}$ time interval the tissue within the lesioned area is deteriorated the expression within the lesioned area was measured in sections where some of the tissue was left. At the other time points the lesion was encircled and measured. The sense values were in all cases background values. Pictures have been taken directly from the $\mathrm{x}$-ray film.

For statistical analysis multiple $t$ test was used. As a basis for the statistical tests served the mean values of the measured specific transmissions and their standard deviations.

\section{Results}

\section{Distribution of the thioredoxin $M R N A$ in the rat brain}

The thioredoxin mRNA is widely distributed throughout the rat brain. In all areas investigated the thioredoxin mRNA is expressed in nerve cells (Fig. 2).

Telencephalon. High expression can be seen in the cortex from the frontal to the occipital level. This expression is localized in the cingulate cortex, the frontal cortex, the parietal cortex, the temporal cortex, the piriform cortex, the entorhinal cortex and the amygdala. There is no significant difference in optical density from bregma $4.20 \mathrm{~mm}$ to bregma $-0.40 \mathrm{~mm}$ (Fig. 1a). The highest expression shows the piriform cortex, especially at bregma $3.20 \mathrm{~mm}$ to $-0.40 \mathrm{~mm}$ (Fig. 1a). This labeling was due to expression of the gene in the granule cells. There was no variation in rostro-caudal direction as seen by measure-

\footnotetext{
Figure 1. Thioredoxin mRNA distribution in selected regions of the rat brain. $a$, Thioredoxin gene expression in the rat cerebral cortex. $c g$, Cingulate cortex; $f r$, frontal cortex; par, parietal cortex. In the piriform cortex (pir) the gene is very highly expressed whereas in the caudate putamen $(C P u)$ the expression is only slightly above background level (bregma, $1.7 \mathrm{~mm}$ ). $b$, The subfornical organ ( $S F O)$ and the supraoptic nucleus $(\mathrm{SO})$ are moderately expressing thioredoxin mRNA (bregma, $-0.9 \mathrm{~mm}$ ). $c$, The paraventricular hypothalamic nucleus $(P a)$ is one of the nuclei expressing the highest amounts of thioredoxin mRNA. The rostral part of the supraoptic nucleus ( $S O$ ) is labeled by thioredoxin mRNA (bregma, $-2.0 \mathrm{~mm}) . d$, In the CA3-CA4 region of the hippocampal formation and the dentate gyrus $(D G)$ the thioredoxin gene is highly expressed, whereas the CA1 and CA2 region shows very low gene expression. Within the thalamus the gene is moderately expressed in the ventroposteromedial thalamic nucleus $(V P M)$, in the hypothalamus the ventromedial hypothalamic nucleus $(V M H)$ and the arcuate nucleus (Arc) are strongly labeled by the thioredoxin mRNA probe (bregma, $-3.2 \mathrm{~mm}$ ). $e$. The substantia nigra pars compacta $(S N C)$ is moderately positive for thioredoxin mRNA (bregma, $-5.3 \mathrm{~mm}$ ). $f$, The locus coeruleus $(L C)$ is one of the regions with the highest thioredoxin mRNA expression. Mo5, Motor trigeminal nucleus (bregma, $-9.8 \mathrm{~mm}$ ). $g$, At bregma $-10.5 \mathrm{~mm}$ the facial nucleus (7) is strongly positive for thioredoxin mRNA. $h$, The medulla oblongata exhibits structures moderately and highly expressing the thioredoxin gene, that is, the nucleus of the solitary tract (Sol), the dorsal motor nucleus of the vagus $(10)$, the hypoglossal nucleus (12) and in the medial part as well as the lateral parts of the reticular formation (LRt) and the inferior olive $(I O)$ (bregma, $-13.7 \mathrm{~mm}$ ).
} 

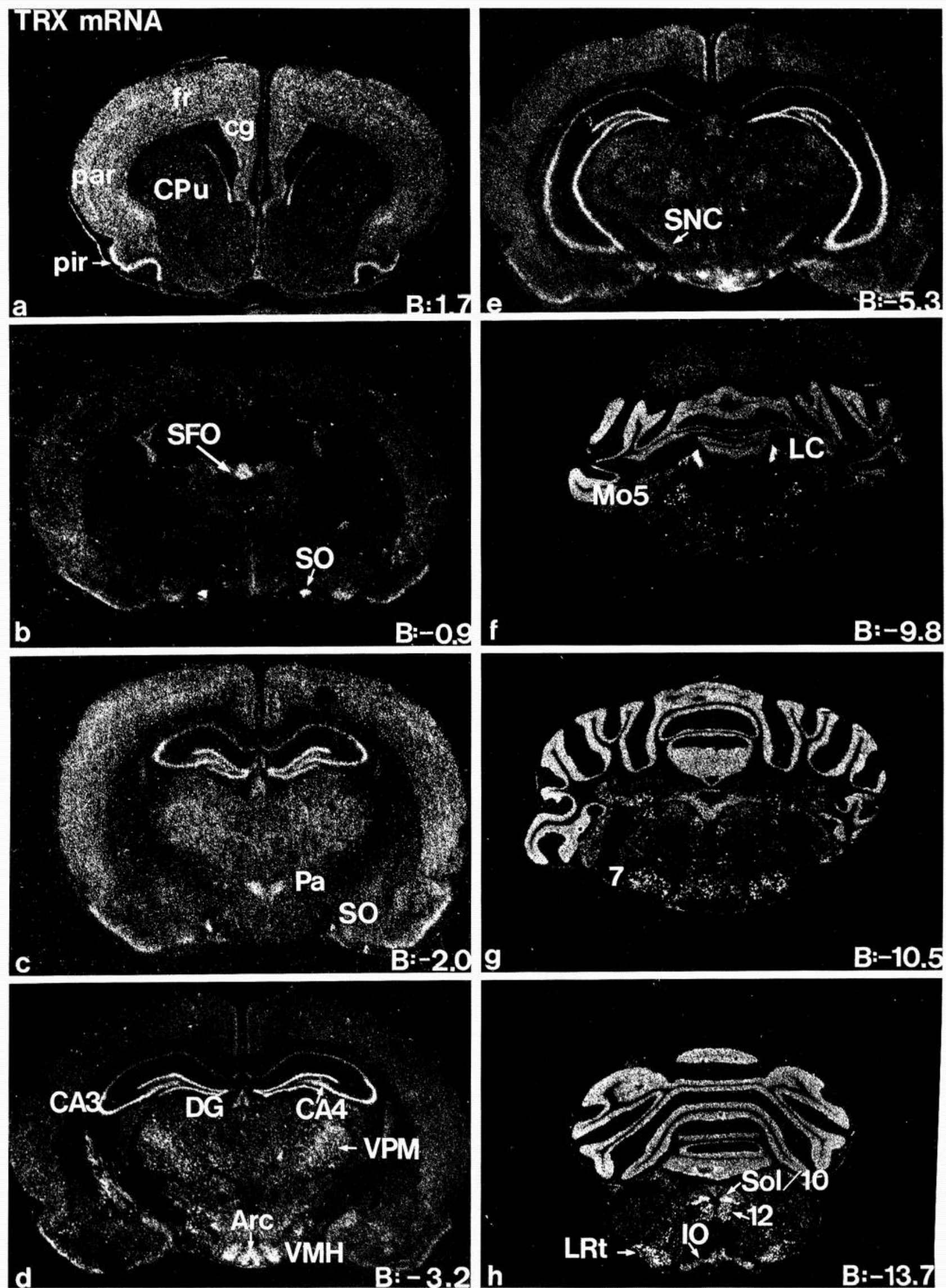
Figure 2. Cellular localization of thioredoxin mRNA using emulsion and counterstaining with cresyl violet. $a$, In the piriform cortex thioredoxin mRNA signals are seen in the densely packed nerve cells (arrows). $b$, A patchy distribution of the signals for thioredoxin mRNA in the epithelial cells of the choroid plexus in the 4 th ventricle $(4 \mathrm{~V})$ is seen (arrows). $c$, Within the paraventricular hypothalamic nucleus the thioredoxin gene is expressed in nerve cell bodies (arrows). $d$, In the ventral posterolateral thalamic nucleus the grains are localized over the big nerve cells (arrows). $e$, In the CA3 region of the hippocampal formation the grains are localized over the nerve cell nuclei (arrows). $f$, In the inferior olive the gene is expressed in large nerve cell bodies (arrows). $g$, The big nerve cells of the locus coeruleus contain the signals for thioredoxin mRNA (arrows). $h$, A big nerve cell of the nucleus tractus solitarius exhibiting the mRNA signal for thioredoxin (arrow), small glial cell nuclei do not express thioredoxin (arrowhead). Scale bar, $10 \mu \mathrm{m}$.
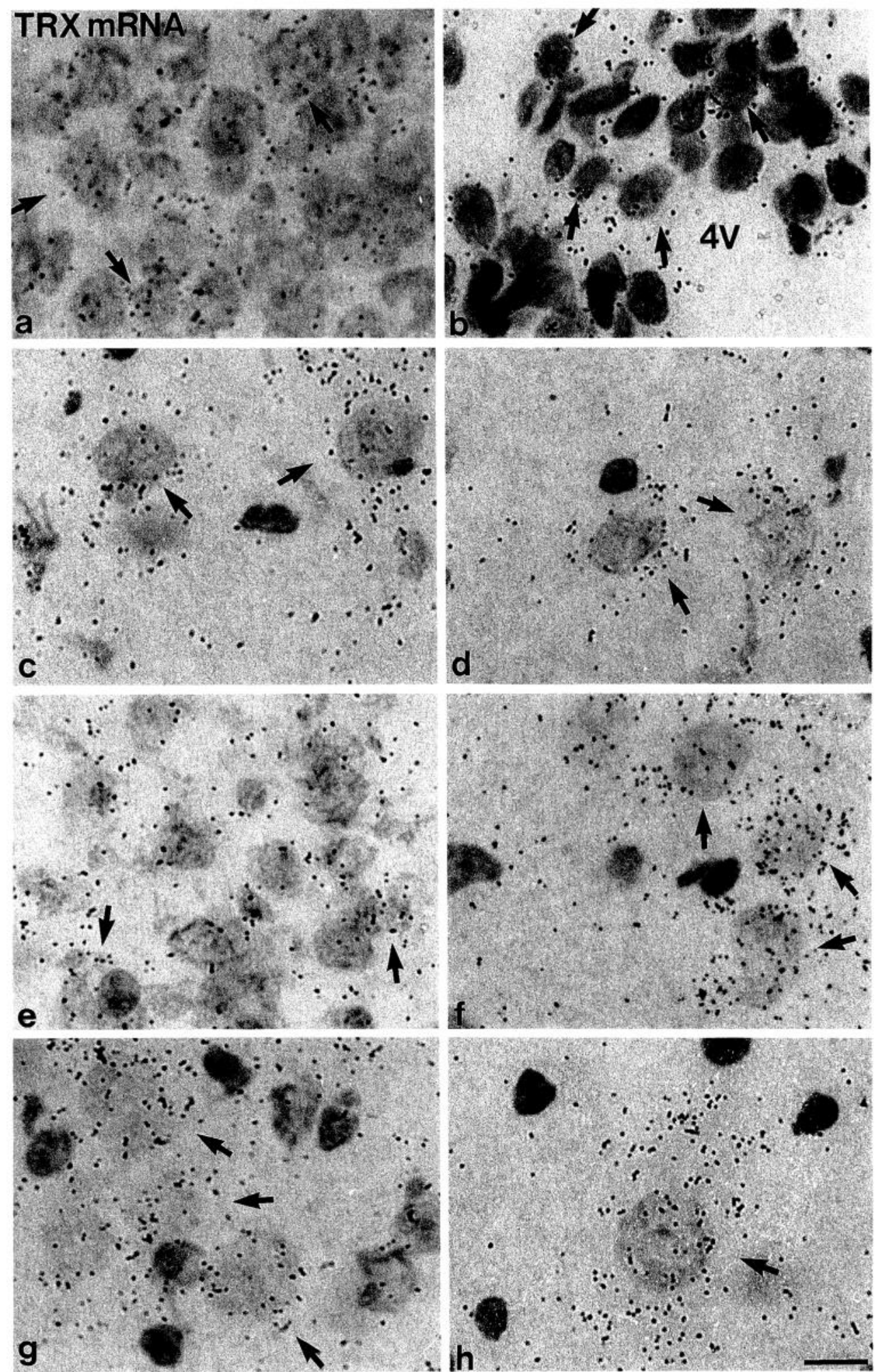

ments between bregma $3.20 \mathrm{~mm}$ to bregma $-0.40 \mathrm{~mm}$ (Fig. $1 a)$. The caudate putamen shows very low expression of the message, whereas the ependymal cells of the lateral ventricle express thioredoxin (Fig. 1a) (Table 1).

In the hippocampal formation the thioredoxin gene is mainly expressed in the nerve cells of the CA3 region but also in the CA4 region and the granule cells of the dentate gyrus. All regions show comparable optical densities. The measurements are made at bregma $-2.80 \mathrm{~mm}$ to $-3.00 \mathrm{~mm}$ (Fig. $1 b$ ). Very low amounts of thioredoxin mRNA expression have been observed in the CA1 region (Fig. $1 b$ ).

The basal ganglia including caudate putamen, globus pallidus and ventral pallidum show expression of the thioredoxin gene only slightly above background. Structures related to basal gan- 
Table 1. Distribution of thioredoxin mRNA levels in the rat brain as determined with microdensitometry

\begin{tabular}{|c|c|c|}
\hline \multirow[b]{2}{*}{ Area } & \multicolumn{2}{|l|}{ Optical density } \\
\hline & Mean \pm SD & $n$ \\
\hline \multicolumn{3}{|l|}{ Telencephalon } \\
\hline \multicolumn{3}{|l|}{ Cerebral Corttex } \\
\hline Cingulate cortex & $0.104 \pm 0.018$ & 5 \\
\hline Frontoparietal cortex & $0.090 \pm 0.019$ & 5 \\
\hline Piriform cortex & $0.129 \pm 0.038$ & 5 \\
\hline \multicolumn{3}{|l|}{ Basal ganglia } \\
\hline Caudate putamen & $0.049 \pm 0.026$ & 3 \\
\hline \multicolumn{3}{|l|}{ Preoptic region } \\
\hline Medial preoptic area & $0.141 \pm 0.027$ & 2 \\
\hline Magnocellular preoptic nuc. & $0.101 \pm 0.018$ & 1 \\
\hline \multicolumn{3}{|l|}{ Diencephalon } \\
\hline \multicolumn{3}{|l|}{ Hypothalamus } \\
\hline Supraoptic nucleus & $0.123 \pm 0.046$ & 1 \\
\hline Paraventricular hypothalamic nucleus & $0.337 \pm 0.076$ & 1 \\
\hline Arcuate nucleus & $0.224 \pm 0.052$ & 2 \\
\hline Ventromedial hypothalamic nucleus & $0.164 \pm 0.042$ & 3 \\
\hline \multicolumn{3}{|l|}{ Thalamus } \\
\hline Medial habenula & $0.163 \pm 0.023$ & 2 \\
\hline Subthalamic nucleus & $0.205 \pm 0.099$ & 1 \\
\hline \multicolumn{2}{|l|}{ Ventral posteriolat./posteriomed. } & 2 \\
\hline Ventrolat/Ventromed. thal. nuc. & $0.111 \pm 0.021$ & 2 \\
\hline \multicolumn{3}{|l|}{ Mesencephalon } \\
\hline Substantia nigra pars compacta & $0.115 \pm 0.058$ & 1 \\
\hline \multicolumn{3}{|l|}{ Pons } \\
\hline Locus coeruleus & $0.379 \pm 0.123$ & 2 \\
\hline Pontine nuclei & $0.232 \pm 0.084$ & 2 \\
\hline Motor trigeminal nuc. & $0.168 \pm 0.045$ & 2 \\
\hline \multicolumn{3}{|l|}{ Medulla oblongata } \\
\hline Inferior olive & $0.252 \pm 0.080$ & 3 \\
\hline Nucleus of the solitary tract & $0.384 \pm 0.113$ & 2 \\
\hline Hypoglossal nucleus & $0.285 \pm 0.044$ & 2 \\
\hline Fascial nucleus & $0.235 \pm 0.037$ & 2 \\
\hline Lateral reticular nuc. & $0.178 \pm 0.030$ & 3 \\
\hline Choroid plexus (4th ventricle) & $0.126 \pm 0.038$ & 2 \\
\hline \multicolumn{3}{|l|}{ Circumventricular organs } \\
\hline Subfornical organ & $0.148 \pm 0.046$ & 1 \\
\hline \multicolumn{3}{|l|}{ Hippocampal formation } \\
\hline CA1 & $0.053 \pm 0.013$ & 2 \\
\hline $\mathrm{CA} 3 / \mathrm{CA} 4$ & $0.149 \pm 0.040$ & 3 \\
\hline Dentate gyrus & $0.152 \pm 0.051$ & 3 \\
\hline
\end{tabular}

$n$, Number of rostro-caudal levels examined. Means \pm SD are shown out of four rats. In each rat and each area at least three sections were measured.

glia with regard to function such as the substantia nigra and the subthalamic nucleus present more intense labeling. Substantia nigra is only labeled within the pars compacta as illustrated at bregma $-4.80 \mathrm{~mm}$ to $-5.00 \mathrm{~mm}$ (Fig. 1c) and shows less labeling than the subthalamic nucleus at bregma $-3.80 \mathrm{~mm}$ to $-4.16 \mathrm{~mm}$. The magnocellular preoptic nucleus as well as the nucleus of the horizontal limb of the diagonal band shows a moderate expression of the message.

Diencephalon. The thioredoxin mRNA was moderately expressed within all the preoptic nuclei. Thalamic and hypothalamic regions contain moderate to high amounts of thioredoxin mRNA. Highest expression levels were observed in the para- ventricular hypothalamic nucleus (Fig. 1f), the arcuate nucleus (Fig. $1 b$ ) and the subthalamic nucleus. Other regions like the supraoptic nucleus (Fig. $1 f$ ), the ventromedial hypothalamic nucleus (Fig. $1 b$ ), the medial habenula, the ventralposteriolateral/ posteriomedial thalamic nucleus (Fig. $1 b$ ) and the ventrolateral/ ventromedial thalamic nucleus were moderately labeled.

Pons. The pontine nuclei (bregma: $-6.80 \mathrm{~mm}$ to $-7.00 \mathrm{~mm}$ ) are among the most intensely labeled structures in the rat brain. Moreover, the locus coeruleus (bregma: $-10.04 \mathrm{~mm}$ to -9.7 $\mathrm{mm}$ ) is the structure with the most intense labeling among all structures measured (Fig. $1 \mathrm{~h}$ ) and the motor nucleus of the trigeminal nerve (bregma: $-9.7 \mathrm{~mm}$ ) shows moderate expression of the thioredoxin gene (Fig. 1h).

Medulla oblongata. The lateral reticular nucleus (LRt) (Fig. $1 d, g$ ) (bregma: $-13.7 \mathrm{~mm}$ ), the nucleus of the solitary tract (NTS) (lateral and medial part, bregma: $-13.8 \mathrm{~mm}$ to -13.6 $\mathrm{mm}$ ), the fascial nucleus (bregma: $-10.5 \mathrm{~mm}$ to $-11.0 \mathrm{~mm}$ ) and the inferior olive (IOC) (bregma: $-13.7 \mathrm{~mm}$ ) were the most intensely labeled structures in the medulla oblongata (Fig. 1d). Within the medulla oblongata, the NTS shows strong gene expression, whereas the IOC, fascial nucleus, and the LRt were moderately labeled.

The 4th ventricle choroid plexus (bregma: $-13.2 \mathrm{~mm}$ ) shows moderate thioredoxin mRNA expression.

Circumventricular organs. The subfornical organ (bregma: $-1.4 \mathrm{~mm}$ ) of the rat brain is moderately labeled (Fig. $1 e$ ), whereas no clear signal is observed in the median eminence and the area prostrema.

\section{Partial meso-diencephalic hemitransection}

The thioredoxin mRNA levels are highly upregulated at $24 \mathrm{hr}$ around the lesion site and also in the surrounding cortical hemisphere (retrosplenial and frontoparietal cortices) of the ipsilateral side. After $72 \mathrm{hr}$ the increased mRNA signal is more restricted to the lesion site and only the frontoparietal part of the cerebral cortex is still activated. At the $7 \mathrm{~d}$ time interval the expression of the thioredoxin gene within the cortical areas is almost normal. However, the cells within the lesioned area still show an increased labeling. Fourteen days after the surgery the thioredoxin mRNA levels are normalized (Figs. 3, 4). The CA1 region of the hippocampal formation exhibits a higher level of thioredoxin mRNA expression $24 \mathrm{hr}$ after injury. This expression is back to normal control values after $72 \mathrm{hr}$.

\section{Discussion}

Thioredoxin mRNA levels are widely distributed throughout the rat brain. The highest expression levels have been observed in the piriform cortex, the dentate gyrus, the CA3/CA4 region of the hippocampal formation, the locus coeruleus as well as in some regions involved in neuroendocrine and/or cardiovascular control such as the paraventricular hypothalamic nucleus and the nucleus of the solitary tract. There is little known until now about the functional importance of thioredoxin gene expression in these regions. Since thioredoxin is a general protein disulfide oxido-reductase (Holmgren, 1979) and may regulate protein activity by "thiol-redox control" (Holmgren, 1985, 1989) it should have functions in signal transduction. Indeed, Deiss et al. (1991) cloned the thioredoxin gene, when the signal transduction pathway for interferon was analyzed by genetic techniques. It is interesting to note that thioredoxin expression is particularly abundant in regions with high energy demands or high activity involving redox reactive metabolites such as the substantia nigra 


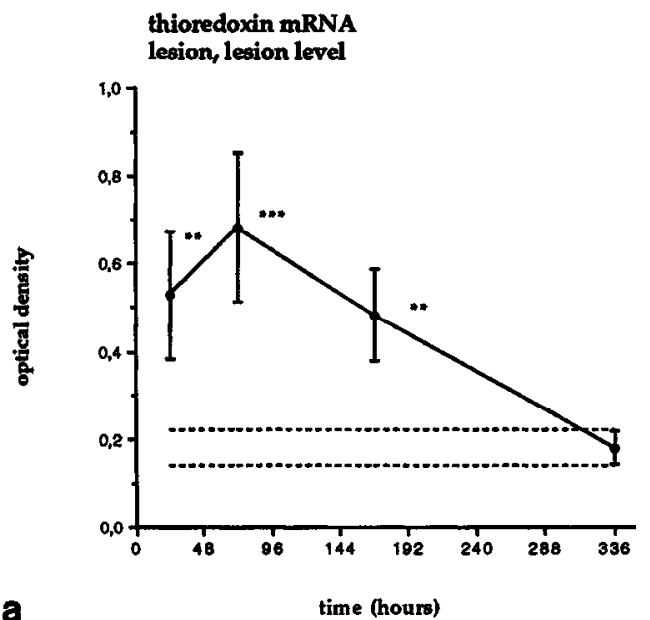

a

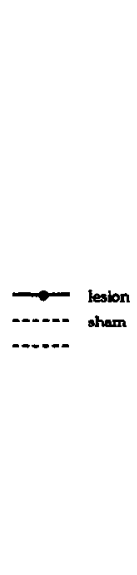

b
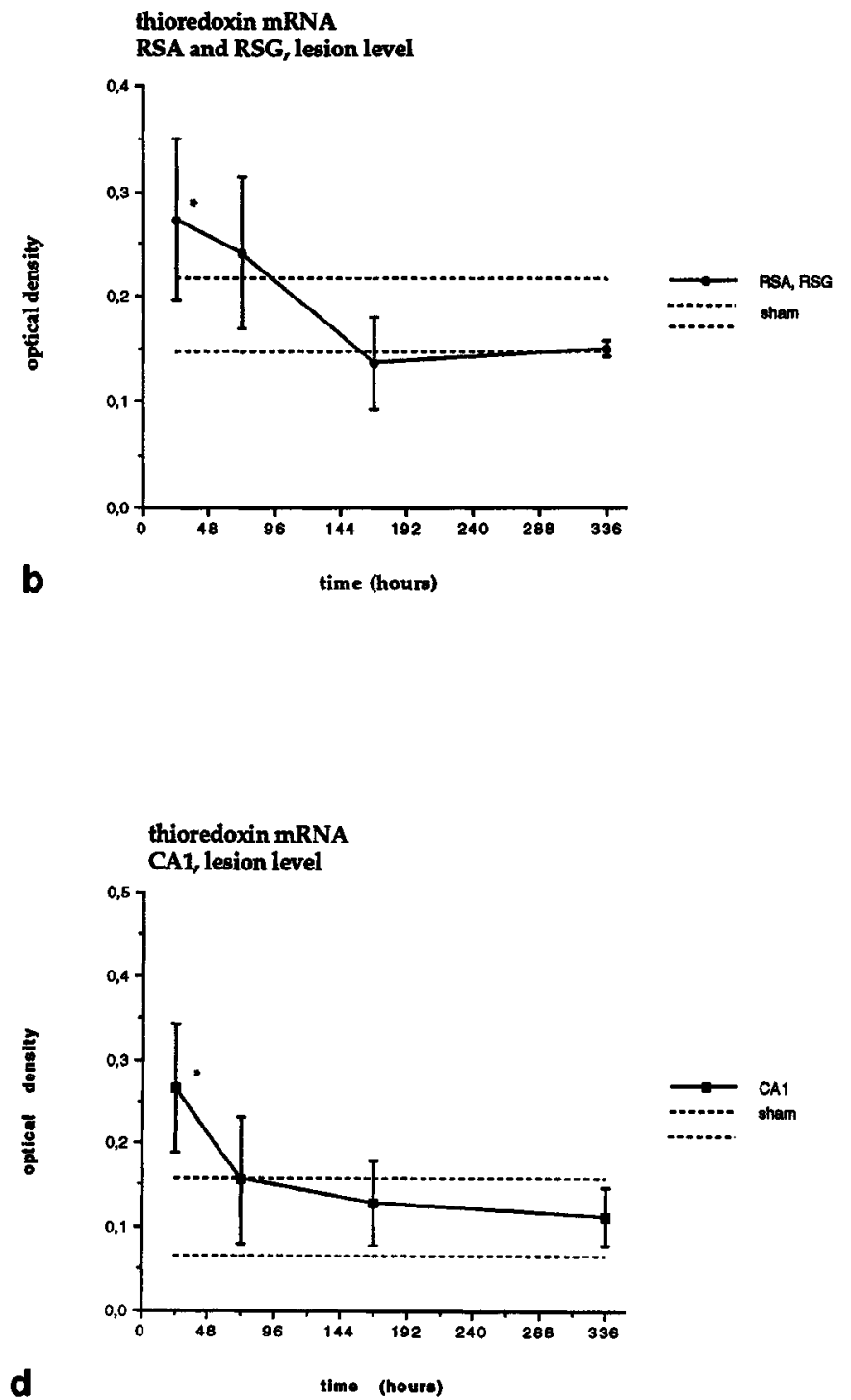

Figure 3. Time-dependent expression of thioredoxin mRNA after unilateral partial hemitransection. The thioredoxin mRNA levels of sham operated animals (sham) were expressed as optical densities \pm SD (shown as parallel dotted lines). The thioredoxin mRNA expression after hemitransection was expressed as optical densities (means $\pm S D, n=4)(0)$. $a$, Lesioned area (bregma: $-2.3 \mathrm{~mm}$ to $-3.1 \mathrm{~mm}$ ); $b$, retrosplenial agranular cortex $(R S A)$ and retrosplenial granular cortex $(R S G)$ (bregma: $-2.3 \mathrm{~mm}$ to $-3.1 \mathrm{~mm}$ ); and $c$, frontoparietal cortex $(F r, P a r)$ (bregma: $-2.3 \mathrm{~mm}$ to -3.1 $\mathrm{mm}$ ). $d$, CA1 region of the hippocampal formation (bregma: $-2.3 \mathrm{~mm}$ to $-3.1 \mathrm{~mm}$ ). The measurement for the different regions was undertaken as shown in Figure $4 a$. Statistical analysis was made using multiple $t$ test $(* * *, p<0.001 ; * *, p<0.01 ; *, p<0.05)$.

and the subthalamic nucleus. Roles in keeping enzymes active in the presence of oxidizing redox active substrates or a direct role in regulating receptor and enzyme function is suggested. This would include information handling in the normal uninjured brain. In contrast, the CAl region of the hippocampal formation, very well known for the vulnerability of its neurons to oxidative stress (Leifer and Kowall, 1993; Ordy et al., 1993; Neumann-Haefelin et al., 1994), is characterized by very low thioredoxin expression. This could be in part the reason for its vulnerability to situations like ischemia. Indeed, it has been shown, that glutathione is essential for hippocampal neurons to recover from damage by free radicals (Pellmar et al., 1992).

Previously, the calf brain was found to contain thioredoxin ( $0.05 \%$ of wet weight) determined by radioimmunoassay (Holmgren and Luthman, 1978). Immunohistochemical investigations showed thioredoxin and thioredoxin reductase to be present in the nerve cells in the rat brain (Rozell et al., 1985). Furthermore, thioredoxin and thioredoxin reductase were found to be transported by axoplasmic transport in the rat sciatic nerve (Stemme et al., 1985a). These results and the present investigation with localization of thioredoxin mRNA give evidence for the continued synthesis of this protein by the nerve cells themselves. Indeed, since thioredoxin has been shown to be secreted from human B-cells and several other cell types (Ericson et al., 1992; Sitia et al., 1992), secretion from nerve cells may help to protect cells via anti-oxidative roles of thioredoxin together with glutathione peroxidase. It was recently shown (Björnstedt et al., 1994) that the thioredoxin and glutaredoxin systems are efficient electron donors to human plasma glutathione peroxidase, which operates in serum devoid of glutathione.

The present results demonstrate thioredoxin mRNA levels in ependymal cells of the 3rd ventricle and in epithelial cells of the choroid plexus as well. Here a patchy pattern of gene expression was evident. Thioredoxin immunoreactivity has previously been 

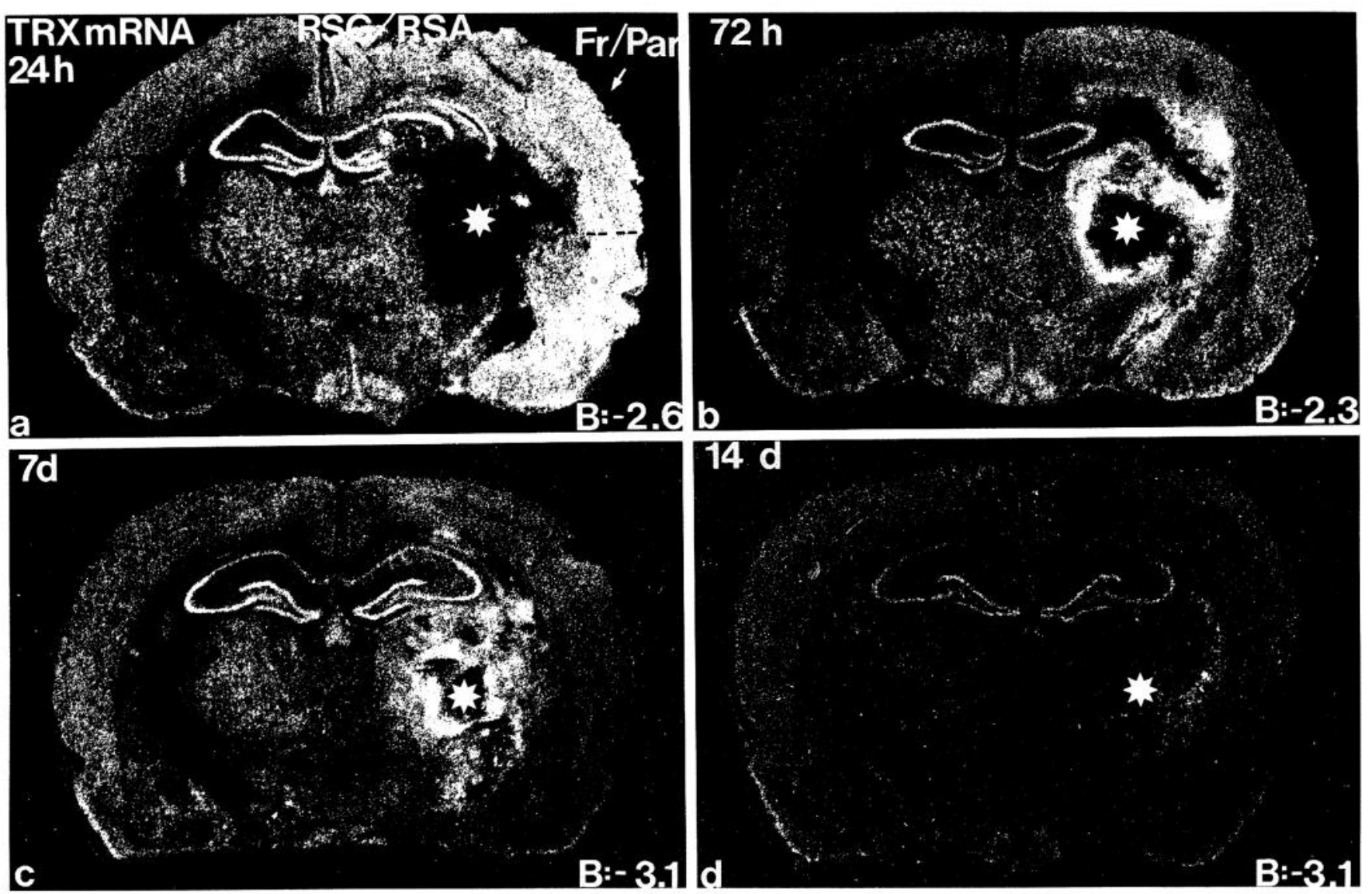

Figure 4. Illustration of the upregulation of thioredoxin mRNA expression after unilateral partial hemitransection as revealed by in situ hybridization. $a$, Thioredoxin mRNA $24 \mathrm{hr}$ after injury, RSG/RSA-retrosplinal granular and agranular cortices, Fr/Par-fronto-parietal cortex. The white dotted line shows the ventral border between RSA/RSG and Fr, and the black dotted line shows the border for measurement of the fronto-parietal cortex. $b$ illustrates the thioredoxin gene expression $72 \mathrm{hr}$ after the injury; $c$ demonstrates the thioredoxin mRNA after $7 \mathrm{~d}$. The area surrounding the lesion is strong labeled for thioredoxin mRNA; $d, 14 \mathrm{~d}$ after the lesion. The thioredoxin mRNA levels have become normalized (*, lesion site).

found in many epithelial cells (Rozell et al., 1985; Hansson et al., 1988; Padilla et al., 1992) and in the secreting cells of the choroid plexus as well (Rozell et al., 1984). The function of thioredoxin expressed in the epithelial cells of the choroid plexus and ependymal cells of the ventricle may be related to their cell metabolism itself. Additionally, the secretion of thioredoxin into the cerebrospinal fluid may lead to the protection of nerve cells from oxidation by environmental influences like reactive oxygen intermediates via bulk flow into the extracellular fluid, thus maintainig the microenvironment of the brain cells (Nilsson et al., 1992). Moreover, thioredoxin could directly influence the secretory state of the epithelial cells of the choroid plexus and the ependymal cells of the ventricle, probably via control of cytoplasmic redoxbalance, as has been shown for the epithelial cells of the gastric mucosa and exocrine and endocrine pancreas (Hansson et al., 1986, 1988). It may also have a function in supporting the transport of substances from the blood to the CSF and vice versa by influencing the redox state of the transporter systems in the choroid plexus (Ericson et al. 1992).

Thioredoxin mRNA was also detected in the nigral dopaminergic cells of the zona compacta, which may give it a putative role in Parkinson's disease as suggested previously by Endoh et al. (1993).

Under pathophysiological conditions such as head trauma (mechanical injury), it is shown in the present article that the expression of the thioredoxin gene is strongly induced in the lesioned area reaching into cortical regions of the ipsilateral hemisphere. The CA1 region of the hippocampal formation shows only a slight transient upregulation of the thioredoxin mRNA after the lesion. However, the cellular location of this increased thioredoxin mRNA signal still remains to be determined, but it may be linked to activated glial cells since the region surrounding the lesion is filled up with activated astroglial and microglial cells. However, in the uninjured brain the glial cells have been shown to lack thioredoxin immunoreactivity (Rozell et al., 1985; Hansson et al., 1989). The thioredoxin mRNA induction is an early event and occurs already $24 \mathrm{hr}$ after injury. Since reactive oxygen intermediates play a crucial role in tissue damage after injury, the upregulation of the thioredoxin gene expression may be due to the involvement of the thioredoxin in protecting the lesioned area from active oxygen intermediates. As a result of such active oxygen intermediates, the methionine residues may be oxidized to methionine sulphoxide residues in proteins and thioredoxin together with methionine sulphoxide reductases will repair such proteins. Furthermore, many proteins will contain artificial disulfide bonds which may be reduced by thioredoxin reductase NADPH and thioredoxin. It appears that thioredoxin mRNA is induced following some signalling on the gene level involving increased oxidative stress via an as yet unknown mechanism. Particularly, interesting has 


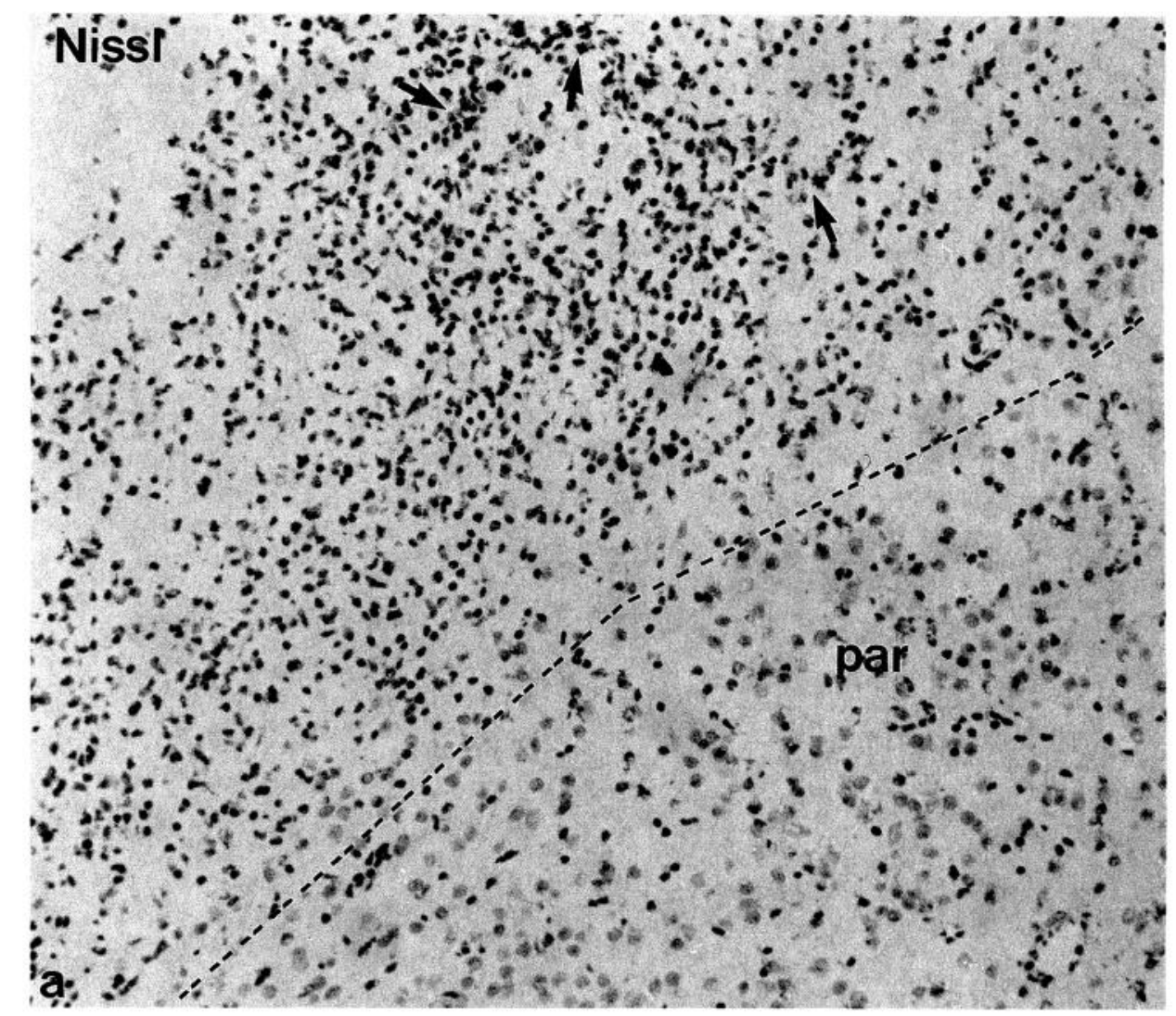

Figure 5. Cresyl violet staining of the hemitransected region $7 \mathrm{~d}$ after the partial unilateral hemitransection. $a$, Morphology of the lesion near the parietal cortex (par). The lesioned region (on the left-hand side of the dotted line) demonstrates densely packed small cell nuclei probably related to different types of glial cells (arrows). $b$, Densely packed small glial cell nuclei are characteristric for the tissue repair via gliosis within the lesioned area (arrows). Scale bar, $50 \mu \mathrm{m}$.

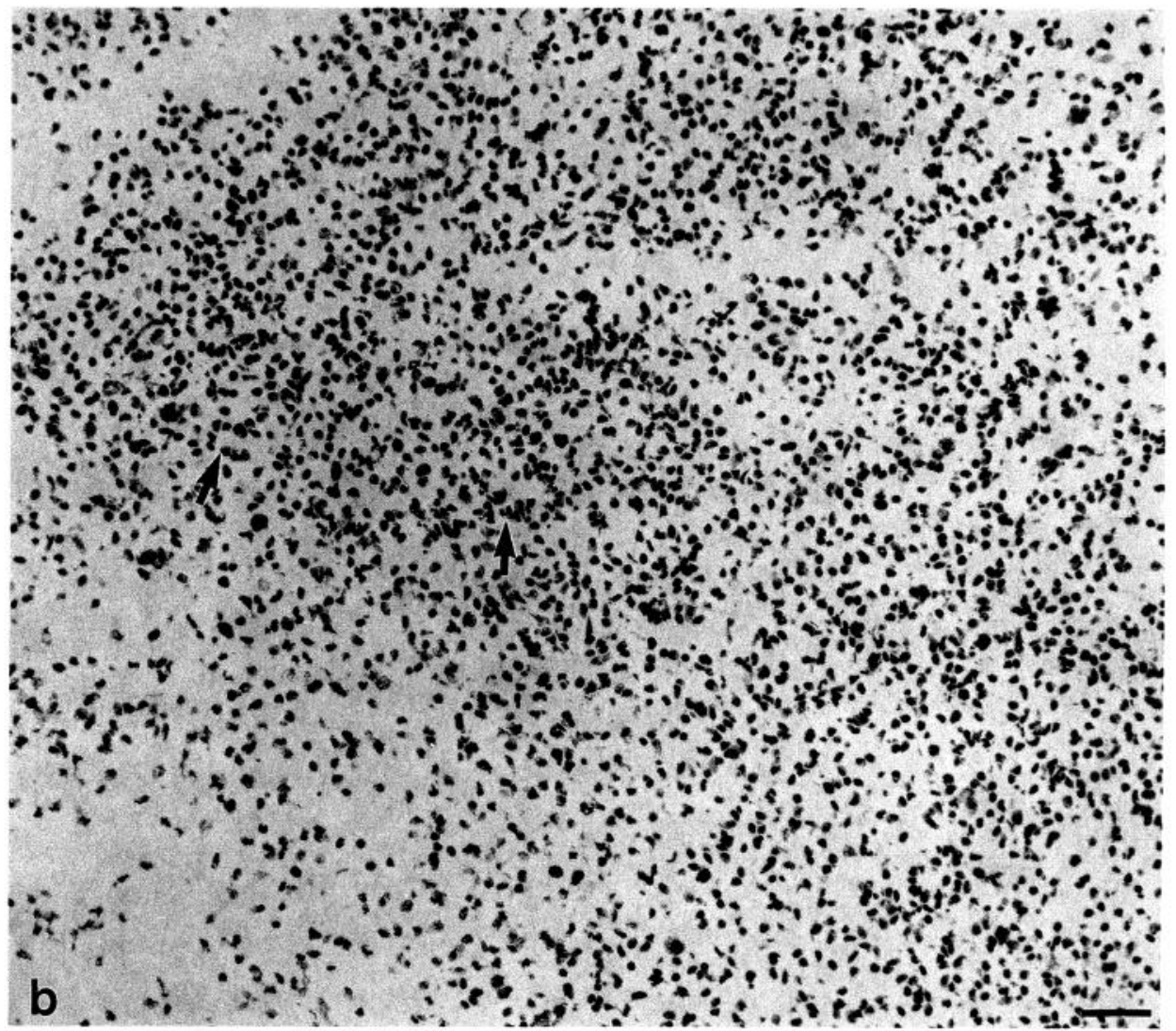


been the information in recent years that thioredoxin is involved in the regulation of a number of transcription factors including NF-kB, AP-1, TF3C, TZLF1, and myb. In the case of NF- $k$ B, it has becn shown both in vitro and in vivo that human thioredoxin is responsible for the activation of the DNA binding properties by specifically reducing a disulfide bond involving a critical cysteine residue at position 62 in the P50 subunit (Abate et al., 1990; Matthews et al., 1992; Hayashi et al., 1993; Mitomo et al., 1994). The slight and transient increase in thioredoxin mRNA in the CAl subfield of the hippocampus after the lesion may be one reason for its high vulnerability to increased oxidative stress and to the late onset of neuronal activation as seen by c-fos expression (Neumann-Haefelin et al. 1994).

It should also be noted that thioredoxin has been identified as a highly expressed cytokine-like factor in activated T- and B-cells which upregulates the interleukin-2 receptor a-chain and interleukin-2, both of which are under the transcriptional control of NF-kB (Tagaya et al., 1989; Wakasugi et al., 1990). A protective role for damaged neuronal cells may thus be visioned for thioredoxin secreted from glial cells or in particular from microglia/macrophages in the damaged ipsilateral area. Direct involvement of thioredoxin in transcriptional control activity with a variety of genes in the injured area in activated cells is a likely result. Repair mechanisms would also require DNA synthesis and thioredoxin is a hydrogen donor for ribonucleotide reductase and a redox regulator of the enzyme. In the case of injury, it may be able to supply the deoxyribonucleotides for DNA synthesis in dividing glial cells and channel nucleotides for repair in nerve cells.

Several recent reports suggest that thioredoxin may have important, but as yet undefined co-cytokine activities under pathophysiological conditions involving oxidative stress. This includes observations with hydrogen peroxide (Spector et al., 1988 ) as well as with TNF- $\alpha$ (Matsuda et al., 1991) or experimental ischemia (Endoh et al., 1993; Tomimoto et al., 1993). Thioredoxin has also been shown to modify the glucocorticoid receptor to a steroid binding site by reduction (Grippo et al., 1985). A specific role for thioredoxin in reticular site initiation of protein synthesis has been shown (Holmgren, 1985).

In conclusion, the thioredoxin gene expression has been shown to be widely distributed but preferentially located in distinct nerve cell populations in the rat brain. It is also strongly induced under pathophysiological conditions such as mechanical injury. Thus, one role of thioredoxin may be to form an essential signal molecule and functional part of the DNA regeneration processes in the activated glial cells of the brain, which remains to be determined in more detail.

\section{References}

Abate C, Patel L, Rauscher FJ III, Curran T (1990) Redox regulation of fos and jun DNA-binding activity in vitro. Science 249:11571160.

Agnati LF, Fuxe K, Calza L, Zini I, Benfenati F, Farabegoli C, Goldstein M (1983) Chronic treatment with L-dopa plus carbidopa in hemitransected rats: preferential effects at intact dopamine synapses leading to behavioural signs of dopamine receptor supersensitivity. Acta Physiol Scand 199:27-34.

Björnstedt M, Xue J, Huang W, Åkesson B, Holmgren A (1994) The thioredoxin and glutaredoxin systems are efficient electron donors to human plasma glutathione peroxidase. J Biol Chem 269: $29382-$ 29384.

Bunnemann B, Iwai N, Metzger R, Fuxe K, Inagami T, Ganten D (1992) The distribution of angiotensin II AT 1 receptor subtype mRNA in the rat brain. Neurosci Lett 142:155-158.
Deiss LP, Kimchi A (1991) Genetic tool used to identify thioredoxin as a mediator of a growth inhibitory signal. Science $252: 117-120$.

Endoh M, Kunishita T, Tabira T (1993) Thioredoxin from activated macrophages as a trophic factor for central cholinergic neurons in vilro. Biochem Biophys Res Commun 192:760-765.

Ericson ML, Hörling J, Wendel-Hansen V, Holmgren A, Rosen A (1992) Secretion of thioredoxin after in vitro activation of human B cells. Lymphokine Cytokine Res 11:201-207.

Fuxe K, Janson AM, Jansson A, Andersson K, Eneroth P, Agnati LF (1990) Chronic nicotine treatment increases dopamine levels and reduces dopamine utilization in substantia nigra and in surviving forebrain dopamine nerve terminal systems after a partial di-mesencephalic hemitransection. Naunyn-Schmiedeberg's Arch Pharmacol 341:171-181.

Grippo JF, Holmgren A, Pratt WB (1985) Proof that the endogenous, hcat-stable glucocorticoid receptor-activating factor is thioredoxin. $J$ Biol Chem 260:93-97.

Hansson HA, Holmgren A, Rozell B, Täljedal LB (1986a) Immunohistochemical localization of thioredoxin and thioredoxin reductase in mouse exocrine and endocrine pancreas. Cell Tissue Res 245:189195.

Hansson HA, Holmgren A, Rozell B, Stemme S (1986b) Localization of thioredoxin, thioredoxin reductase and ribonucleotide reductase in cells: immunohistochemical aspects. In: Thioredoxin and glutaredoxin systems: structure and function (Holmgren A, et al., eds). New York: Raven.

Hansson HA, Helander HF, Holmgren A, Rozell B (1988) Thioredoxin and thioredoxin reductase show function-related changes in the gastric mucosa: immunohistochemical evidence. Acta Physiol Scand 132:313-320.

Hansson HA, Holmgren A, Norstedt G, Rozell B (1989) Changes in the distribution of insulin-like growth factor $I$, thioredoxin, thioredoxin reductase and ribonucleotide reductase during the development of the retina. Exp Eye Res 48:411-420.

Hayashi T, Ueno Y, Okamoto T ( 1993) Oxidoreductive regulation of nuclear factor $\kappa$ B. J Biol Chem 268:11380-11388.

Holmgren A (1979) Thioredoxin catalyzes the reduction of insulin disulfides by dithiothreitol and dihydrolipoamide. J Biol Chem 254: 9627-9632.

Holmgren A (1985) Thioredoxin. Annu Rev Biochem 54:237-271.

Holmgren A (1989) Thioredoxin and glutaredoxin systems. J Biol Chem 264:13963-13966.

Holmgren A, Luthman M (1978) Tissue distribution and subcellular localization of bovine thioredoxin determined by radioimmunoassay. Biochemistry 17:4071-4077.

Leifer D, Kowall NW (1993) Immunohistochemical patterns of selective cellular vulnerability in human cerebral ischemia. J Neurol Sci 119:217-228.

Lippoldt A, Andbjer B, Rosen L, Richter E, Ganten D, Cao Y, Pettersson RF, Fuxe K (1993) Photochemically induced focal cerebral ischemia in rat: time dependent and global increase in basic fibroblast growth factor mRNA. Brain Res 625:45-56.

Matthews JR, Wahasugi N, Virelizier JL, Yodoi J, Hay RT (1992) Thioredoxin regulates the DNA binding activity of NF- $\mathrm{KB}$ by reduction of a disulfide bond involving cysteine b2. Nucleic Acids Res 20: 3821-3830.

Matsuda M, Matsutani H, Nakamura H, Miyajima S, Yamauchi A, Yonehara S, Uchida A, Irimajiri K, Horiuchi A, Yodoi J (1991) Protective activity of adult $T$ cell leukemia-derived factor (ADF) against tumor necrosis factor-dependent cytotoxicity on U937 cells. J Immunol 147:3837-3841.

Mitomo K, Nakayama K, Fujimoto K, Sun X, Seki S, Yamamoto K (1994) Two different cellular redox systems regulate the DNA-binding activity of the p50 subunit of NF-KB in vitro. Gene 145:197203.

Muller EGD (1991) Thioredoxin deficiency in yeast prolongs $S$ phase and shortens the G1 interval of the cell cycle. J Biol Chem 266: 9194-9202.

Neumann-Haefelin T, Wiessner C, Vogel P, Back T, Hossmann KA (1994) Differential expression of the immediate earla genes c-fos, c-jun, c-junB, and NFI-B in the rat brain following transient forebrain ischemia. J Cereb Blood Flow Metab 14:206-216.

Nilsson C, Lindvall-Axelsson M, Owman C (1992) Neuroendocrine regulatory mechanisms in the choroid plexus-cerebrospinal fluid system. Brain Res Rev 17:109-138. 
Ordy JM, Wegenack TM, Bialobok P, Coleman PD, Rodier P, Baggs RB, Dunlap WP, Kates B (1993) Selective vulnerability and early progression of hippocampal CA1 pyramidal cell degeneration and GFAP-positive astrocyte reactivity in the rat four vessel-occlusion model of transient global ischemia. Exp Neurol 119:128-139.

Padilla CA, Martínez-Galisteo E, López-Barea J, Holmgren A, Bárcena JA (1992) Immunolocalization of thioredoxin and glutaredoxin in mammalian hypophysis. Mol Cell Endocrinol 85:1-12.

Pellmar TC, Roney D, Lepinski DL (1992) Role of glutathione in repair of free radical damage in hippocampus in vitro. Brain Res 583: $194-200$.

Paxinos G, Watson C (1986) The rat brain in stereotaxic coordinates, 2nd ed. New York: Academic.

Ren X, Björnstedt M, Shen B, Ericson ML, Holmgren A (1993) Mutagenesis of structural half-cysteine residues in human thioredoxin and effects on the regulation of activity by selenodiglutathione. Biochemistry 32:9701-9708.

Rozell B, Hansson HA, Luthman M, Holmgren A (1985) Immunohistochemical localization of thioredoxin and thioredoxin reductase in adult rats. Eur J Cell Biol 38:70-86.

Rubartelli A, Bajetto A, Allavena G, Sitia R (1992) Secretion of thioredoxin by normal and neoplastic cells through a leaderless secretory pathway. J Biol Chem 267:24161-24164.

Sanger F, Nicklen S, Coulson AR (1977) DNA sequencing with chain terminating inhibitors. Proc Natl Acad Sci USA 74:5463-5467.

Spector A, Yan GZ, Huang RRC, Mcdermott MJ, Gascoyne PRC, Piget $V$ (1988) The effect of $\mathrm{H}_{2} \mathrm{O}_{2}$ upon thioredoxin-enriched lens epithelial cells. J Biol Chem 263:4-4990.
Stemme S, Hansson HA, Holmgren A, Rozell B (1985) Axoplasmic transport of thioredoxin and thioredoxin reductase in rat sciatic nerve. Brain Res 359:140-146.

Tagaya Y, Maeda Y, Mitsui A, Kondo N, Matsui H, Hamuro J, Brown N, Arai K-I, Yokota T, Wakasugi H, Yodoi J (1989) ATL-derived factor (ADF), an IL-2-receptor/Tac inducer homologous to thioredoxin; possible involvement of dithiol-reduction in the IL-2 receptor induction. EMBO J 8:757-764.

Tomimoto H, Akiguchi I, Wakita H, Kimura J, Hori K, Yodoi J (1993) Astroglial expression of ATL-derived factor, a human thioredoxin homologue, in the gerbil brain after transient global ischemia. Brain Res 625:1-8.

Tonissen KF, Wells JRE (1991) Isolation and characterization of human thioredoxin-encoding genes. Gene 102:221-228.

Wakasugi N, Tagaya Y, Wakasugi H, Mitsui A, Maeda M, Yodoi J, Tursz T (1990) Adult T-cellleukemia-derived factor/thioredoxin, produced by both humanT-lymphotropic virus type I- and EpsteinBarr virus-transformed lymphocytes, acts as an autocrine growth factor and synergizes with interleukin-1 and interleukin-2. Proc Natl Acad Sci USA 87:8282-8286.

Wollman EE, d'Auriol L, Rimsky L, Shaw A, Jacquot JP, Wingfield P, Graber P, Dessarps F, Robin P, Galibert F, Bertoglio J, Fradelizi D (1988) Cloning and expression of a cDNA for human thioredoxin. J Biol Chem 263:15506-15512.

Zoli M, Zini I, Agnati LF, Guidolin D, Ferraguti F, Fuxe K (1990) Aspects of neural plasticity in the central nervous system. I. computer-assisted image analysis methods. Neurochem Int 16:383-418. 